\title{
The Role of Clinical Information Technology in Depression Care Management
}

\author{
Amy M. Kilbourne, ${ }^{1,6}$ Gretchen Flanders McGinnis, ${ }^{2}$ Bea Herbeck Belnap, ${ }^{3}$ \\ Michael Klinkman, ${ }^{4}$ and Marshall Thomas ${ }^{5}$
}

\begin{abstract}
We examine the literature on the growing application of clinical information technology in managing depression care and highlight lessons learned from Robert Wood Johnson Foundation's national program "Depression in Primary Care-Incentives Demonstrations." Several program sites are implementing depression care registries. Key issues discussed about implementing registries include using a simple yet functional format, designing registries to track multiple conditions versus depression alone (i.e., patient-centric versus disease-centric registries) and avoiding violations of patient privacy with the advent of more advanced information technologies (e.g., web-based formats). Finally, we discuss some implications of clinical information technology for healthcare practices and policy makers.
\end{abstract}

KEY WORDS: chronic diseases; depression; information systems; major depressive disorder; quality improvement.

Quality improvement efforts to maximize the delivery of evidence-based depression services are highly reliant on clinical information systems (CIS) to provide timely and accurate information regarding patients' treatment, utilization, and outcomes (Institute of Medicine, 2001; Kilbourne et al., 2004). Such information can be used to ascertain whether quality improvement program goals are being achieved, accreditation standards

\footnotetext{
${ }^{1}$ Center for Health Equity Research and Promotion, VA Pittsburgh Healthcare System, Pittsburgh, PA and also in School of Medicine, University of Pittsburgh, Pittsburgh, PA.

${ }^{2}$ Colorado Access, Denver, CO.

${ }^{3}$ Center for Research on Health Care, School of Medicine, University of Pittsburg, Pittsburg, PA.

${ }^{4}$ Department of Family Medicine, University of Michigan, Ann Arbor, MI

${ }^{5}$ Colorado Access, Denver, CO and also Associate Professor, University of Colorado Health Sciences System, Denver, CO.

${ }^{6}$ Correspondence should be directed to Amy M. Kilbourne, PhD., MPH., is VA Pittsburgh Center for Health Equity Research and Promotion (151-C), University Drive C, Pittsburgh, PA 15240; e-mail: Amy.Kilbourne@med.va.gov.
}

are being met, and whether patient costs and outcomes are affected by the implementation of programs to improve depression care. One of the most significant barriers to improving and sustaining good depression care is the lack of a sustainable means to collect and maintain information on the care of patients with depression (Kilbourne, Rollman, Schulberg, Herbeck-Belnap, \& Pincus, 2002). The information system, and more specifically, the registry, is a vital tool for collecting valid, feasible, and meaningful data on individuals and for monitoring the health of the overall population (Wagner et al., 2001). Hence, the information system serves as the backbone for efforts to improve the quality of depression care (Pincus, Pechura, Elinson, \& Pettit, 2001).

This paper discusses the importance and growing application of information technology in managing depression, and the lessons learned from the Robert Wood Johnson Foundation (RWJF) Depression in Primary Care Incentives Demonstration Program. In our review of the clinical 
information system and its role in depression care improvement, we focus on the application of registries, or databases used to monitor the care of patients with depression. Registries are often used to facilitate the management of specific patient subpopulations with chronic conditions by collecting and summarizing key information pertinent to their care (Kilbourne et al., 2004). The term "registries" is often used in different contexts; however, our definition concerns a clinical and not research or patient recruitment tool. We then highlight the lessons learned from two RWJF program sites as they have implemented their registry for improving depression care. Finally, we discuss the implementation and ultimate sustainability of CIS and registries in the context of health policy and practice.

\section{BACKGROUND}

Much of the quality improvement research in depression care has been based on the Wagner Chronic Care Model (Wagner, Austin, \& Von Korff, 1996; Wagner et al., 2001), and one of the core components of this Model is the establishment of a registry to monitor patient care and track improvement in chronic illness (including depression management) at the health system level. While a number of recent evaluations of chronic care model interventions for depression included a registry (Bruce et al., 2004; Dietrich et al., 2004; Hunkeler, Meresman, Hargreaves, Fireman, \& Berman, 2000; Katon et al., 1999; Rost, Nutting, Smith, \& Werner, 2000; Rost et al., 2001; Rubenstein et al., 2002; Simon, Ludman, Tutty, Operskalski, \& Von Korff, 2004; Simon, Von Korff, Rutter, \& Wagner, 2000; Unutzer et al., 2002; Wells et al., 2000), they were not designed to be implemented in routine care for the most part. There is a dearth of research on the best practices in constructing, implementing, and ultimately sustaining clinical information system registries for depression care improvement in the real world.

Therefore, to get a sense of the state-of-the-art in clinical information systems registry development and implementation in depression care, we conducted a systematic literature review of published empirical research articles, as well as reviews and concept papers in Medline published within the past 12 years. The review was conducted using key words including "registry", "information system", "information technology," "informatics" "clinical reminders" "data collection" and "chronic illness," "depression/major depressive disorder," or "mental disorders". Additional studies not published in the medical or health policy literature on information system use and chronic disease management were also reviewed.

Fourteen articles were found to be directly relevant, covering topic areas related to the application of information technology or registry use in depression or chronic disease management (Allenby, Matthews, Beresford, \& McLachlan, 2002; Bartels et al., 2002; Bodenheimer et al., 2004; Casalino et al., 2003; Cannon and Allen 2000; Feifer, Ornstein, Nietert, \& Jenkins, 2001; Goldberg et al., 2003; Hunkeler, Westphal, \& Williams, 1995; Mechanic, 2002; Nobel, \& Norman, 2003; Owen et al., 2004; Rollman, 2001; Sperl-Hillen et al., 2004; Unutzer, Choi, Cook, \& Oishi, 2002). Some were concept papers or reviews that addressed how CIS are important components in chronic illness care management (Bartels et al., 2002; Bodenheimer et al., 2003; Mechanic, 2002). One addressed the application of the electronic medical records (EMRs) systems in the Veterans Health Administration (VHA) as a potential tool for quality improvement in mental illness (Owen et al., 2004). The remainder will be discussed in greater detail. Three addressed the use of electronic clinical reminders to prompt primary care clinicians to provide depression care (Cannon, \& Allen, 2000; Hunkeler, Westphal, \& Williams, 1995; Rollman et al., 2001). Of note, the only randomized controlled trials focused on information technology and chronic illness care focused on the application of clinical reminders in depression care improvement (Cannon \& Allen, 2000; Rollman et al., 2001), with mixed results. For example, in a recent empirical study, it was shown that automated reminders to providers for depression care had little impact on improved depression-related outcomes (Rollman et al., 2001).

\section{Empirical Studies}

Nonetheless, few if any randomized controlled trials have been conducted to demonstrate whether the implementation of specific information technology components lead to improved depression (or chronic illness) care processes or outcomes. The remaining studies that were found to be relevant were observational in design. One observational study assessed the use of information technology in 
garnering information on patient health status (Allenby et al., 2002). Allenby et al., (2002) found that computer touch-screen technology is an acceptable and efficient method for obtaining selfreported information on quality of life and psychological distress among cancer patients.

Four additional observational studies focused on identifying the core information technology components associated with chronic illness care implementation in routine care settings (Bodenheimer et al., 2004; Casalino, 2002; Feifer et al., 2001; Sperl-Hillen et al., 2004). Casalino et al. (2003) conducted one of the more comprehensive assessments of information technology adaptation and chronic illness care in a national survey of physician organizations. They found that the majority of sites did not use an information system approach to monitor chronic care, and only used very rudimentary processes, such as the routine assessment of prescribed medications for each patient, medication ordering reminders, laboratory results, or radiology results. Only $15.7 \%$ of physician organizations used a disease registry for their patients with depression, and $12.5 \%$ used clinical reminders for depression care. In contrast, $40.3 \%$ and $31.2 \%$ of these physician organizations had disease registries for diabetes and asthma, respectively, and $38.5 \%$ and $33.9 \%$ used clinical reminders for diabetes or asthma care, respectively, suggesting that the adaptation of depression care information technology may be slower for than for other chronic medical illnesses.

\section{Emerging Information Technologies}

The remaining articles discussed the role of current and emerging technologies in CIS and their application to chronic disease management. Most notably, the VHA is a leader in the development and application of electronic information systems to chronic disease quality improvement in the United States (Hynes et al., 2000). It is one of the few national-based health care providers that utilizes comprehensive medical record systems and claims data on a routine basis to manage and monitor the quality of chronic care of over 4 million veterans in the United States. A recent article discussed the application of VHA's administrative data for monitoring the quality of care for patients with mental disorders based on routinely available visit and prescription data (Owen et al., 2004). In addition, the VHA Office of Quality and Performance has also subcontracted with an external peer review program to conduct EMR reviews on thousands of patients every quarter of key process measures for preventive services, depression and substance use disorders screening, and chronic medical disease management such as diabetes care (e.g., Moreland et al., 2004). The VHA is currently implementing the Care Management Dashboard, a registry embedded into its electronic medical record system that allows providers to review notes, clinical reminders, and graphs of recent laboratory results for a set of patients with certain chronic conditions. Overall, the implementation of advanced technology tools in the VHA has been facilitated by its centralized management practices (a closed, single-payer health care system that has invested in information technology over the past 20 years. Nonetheless, given that the majority of physicians complete at least some of their medical training within a VHA hospital, many will likely want to see similar clinical information technology advances in the clinics and hospitals of their subsequent positions.

Finally, three articles (Goldberg et al., 2003; Nobel \& Norman 2003; Unutzer et al., 2002) discussed the use of emerging information technologies in information systems and chronic illness care management. Nobel and Norman (2003) pointed out that more advanced technologies in computer software, hardware, and networking capabilities have been adapted for chronic care management, notably patient diabetes self-management. Example of technologies that have potential for adaptation in depression care include interactive websites with the ability to track patient progress (Unutzer et al., 2002) or engage patients in the self-care management process (Goldberg et al., 2003), care coordination programs such as registries that utilize clinical reminders and summarize personal health data, and the systematic collection of aggregated, de-identified clinical, administrative, and cost data into comprehensive data sets to monitor the quality and outcomes of the patient population. Goldberg et al., (2003) reports on the implementation of web sites that enable patients to self-manage their diabetes care by accessing their EMRs; uploading lab results blood glucose readings; entering medication, nutrition, and exercise data into an online diary; communicating with providers by using clinical e-mail; and browsing education sites with endorsed content. Moreover, the data provided by patients are reviewed by a nurse practitioner case manager on a 
regular basis to ensure appropriate diabetes management. Moreover, web-based data tracking systems originally designed to facilitate data collection for a multicenter study (Unutzer et al., 2002) may also be also applicable for use in routine care because of the versatile nature of web-based programming and the potential for real-time data.

\section{Registry "Best Practices"}

In addition, there is no clear guidance regarding the minimum requirements for registries to effectively function in routine care. Baumgardner \& Hindmarsh, (2003), in collaboration with the RWJF Improving Chronic Illness Care National Program, evaluated three state-of-the art registries used in care management demonstration programs: The Chronic Disease Management System, The Patient Electronic Care system and DocSite ${ }^{\text {SM }}$ (see Table 1 for a description of these registries). Based on this review, suggest a number of features that registries should have, including: (1) short training time, with uncluttered screens that are easy to navigate, (2) web-based, (3) use of drop-down menus and logic checks, (4) compliant with current HIPAA standards and conform to current standards for internet security and encryption, (5) capacity to support multiple illnesses, (6) use of clinical reminders and practice guidelines, (7) capability to create individual care plans with selfmanagement information and disease severity ratings, (8) capacity to print out summary data on quality and other patient outcomes, and (9) be ideally linked to, but not a substitute for, an electronic medical record. Still, these key registries did not contain all of these recommended features (Baumgardner \& Hindmarsh, 2003). Nonetheless, it has not been fully assessed whether all of these components are necessary, or whether in combination, associated with patient level improvement in the quality of care for depression or other chronic illness.

Overall, findings from this current literature review on information technology registries and depression care suggest the need for empirical studies that assess the effect of adaptation of specific information technology components, notably the use of electronic or web-based systems as registries, on improvements in quality and outcomes for patients with depression. Furthermore, a number of the best practices highlighted by Baumgardner and Hindmarsh

Table 1. Key Features of State-of-the-Art Chronic Care Management Registries (Baumgardner and Hindmarsh, 2003)

\begin{tabular}{|c|c|c|c|c|}
\hline Registry & Reference & Platform & Key Features & Example of Recent Client \\
\hline $\begin{array}{l}\text { Chronic } \\
\text { Disease } \\
\text { Management } \\
\text { System } \\
\text { (CDMS) }\end{array}$ & $\begin{array}{l}\text { Mountain-Pacific } \\
\text { Quality Health } \\
\text { Foundation (http: } \\
\text { //www.mpqhf.org) }\end{array}$ & Web-based & $\begin{array}{l}\text { - Contains protocols and clinical guide- } \\
\text { lines, patient education materials, Med- } \\
\text { icaid claims data, reminder and recall } \\
\text { functions and other clinical data } \\
\text { - Tracks health assessments, can be used } \\
\text { to schedule patient contacts, contains } \\
\text { individualized care plans } \\
\text { - Handles multiple chronic conditions }\end{array}$ & $\begin{array}{c}\text { Indiana Primary Health Care } \\
\text { Association (http://www. } \\
\text { indianapca. org/index.html) }\end{array}$ \\
\hline $\begin{array}{l}\text { Patient } \\
\text { Electronic } \\
\text { care System } \\
\text { (PECS) }\end{array}$ & $\begin{array}{l}\text { http://www.midwest } \\
\text { clinicians.org/ files/ } \\
\text { health/tools/cis_- } \\
\text { PECS-Manual.pdf }\end{array}$ & Client-based & $\begin{array}{l}\text { - Handles multiple chronic conditions } \\
\text { - Encounter note includes: demographics, } \\
\text { vital signs, diagnoses, medications, labs, } \\
\text { diagnostic tests, risk factors, immuni- } \\
\text { zations } \\
\text { - Can generate problem and medication } \\
\text { lists }\end{array}$ & $\begin{array}{l}\text { Bureau of Primary } \\
\text { Care Health Disparities } \\
\text { Collaborative (http://bphc. } \\
\text { hrsa.gov/programs/ } \\
\text { HDCProgramInfo.htm) }\end{array}$ \\
\hline DocSite $^{\text {SM }}$ & $\begin{array}{l}\text { http://www.docsite.com/ } \\
\text { about.htm }\end{array}$ & Web-based & $\begin{array}{l}\text { - Three key products: PatientPlanner } \\
\text { (registry), and patient coaching Care- } \\
\text { Coach }^{\mathrm{TM}} \text { (clinical reminders), and pop- } \\
\text { ulations PopulationPlanner } \\
\text { (performance monitoring) } \\
\text { - PatientPlanner } \\
\text { chronic conditions, includes guideline- } \\
\text { based reminders, patient appointment } \\
\text { reminders, generates patient summaries }\end{array}$ & $\begin{array}{l}\text { United Healthcare; } \\
\text { Blue Cross-Blue } \\
\text { Shield of Mississippi }\end{array}$ \\
\hline
\end{tabular}


and technological advances such as web-base platforms have not been fully implemented in routine care, especially for depression management. Nonetheless, while advances in software, hardware, and networking technologies will make the adaptation of registries more feasible in routine practice, many of these features may require additional considerations regarding patient privacy in mental health care. The case studies below will highlight some of the real-world experiences and challenges in adapting information technologies and registries to improve depression care management.

\section{CASE STUDIES IN REGISTRY IMPLEMENTATION}

We present below two case studies of implementing a clinical information system and registry as part of the RWJF Depression in Primary Care Incentives Demonstration program. They demonstrate the challenges faced when customizing a simple yet functional registry tool to fit a local program's needs while simultaneously attempting to develop a generalizable product that could be used in other programs for chronic illnesses.

\section{Case Study 1: Colorado Access}

Colorado Access is a non-profit managed care organization (MCO) formed in 1994 by a group of safety-net providers. Colorado Access manages care for over 180,000 members including both Medicaid physical and behavioral healthcare contracts. The Access Health Plan (AHP) is responsible for physical healthcare services for 39,000 Colorado Medicaid recipients statewide; and access behavioral care $(\mathrm{ABC})$, manages the behavioral health carveout program for approximately 108,000 members. $\mathrm{ABC}$ is the Mental Health Assessment and Service Agency (MHASA) for the Denver (ABC-D) and Pikes Peak (ABC-PP) regions.

As a health plan and provider of both physical and behavioral health services, Colorado Access is in a unique position to study and develop integrated care programs. Colorado Access has access to a great deal of data on its members, but these data are distributed across multiple different sources. In order to support the RWJF Depression in Primary Care program and provide effective care management services, Colorado Access needed to develop a clinical information system that: (1) serves as a registry to identify and track patients enrolled in the program, (2) captures research and outcome data to fulfill evaluation requirements, (3) serves as a central repository of the clinical and contact information relevant to the care management activities, (4) provides tools for structured assessments, monitoring, and care plans, (5) addresses multiple chronic conditions, and (6) yields reports that support clinical supervision, monitoring of productivity, and provider communication.

\section{Considered Outside Vendors, but Built a Registry from the Ground Up}

At first, Colorado Access planned to incorporate these registry functions into a propriety product purchased from a commercial vendor to support the broader care management activities. Modification of the commercial product, however, proved to be more difficult and costly than anticipated. In order to keep to the prearranged RWJF timeline, Colorado Access' IT development staff decided to build a separate Microsoft Access database registry that included the key components needed for the RWJF project. The plan was to migrate this registry to the commercial care management software program at a later date when time and resources permitted.

The development team was guided by several principles: (1) don't duplicate data unnecessarily, (2) allow the workflows to be flexible and applicable to a variety of different projects, and (3) provide an infrastructure to accommodate ongoing development and expansion. From its inception, the expectation was that the registry program would not be perfect, but should be immediately functional and easily modifiable. This involved a culture change for Colorado Access's IT staff, for whom software development historically involved prolonged assessment and design processes that kept end users at arms length until an often unusable final product was near delivery. Ultimately, it became more important to have something to work with and improve than to have something that is eloquently designed but takes years to complete and meets needs that no longer exist.

The software was developed around the clinical needs of depression care management and involved several Plan-Do-Study-Act (PDSA) quality improvement cycles. In these cycles, the clinical staff used the embryonic registry for a few weeks or months and then provided feedback to the IT 
development team, which then added new functionality. When a new function was added, the PDSA cycle was repeated so everyone involved had the opportunity to suggest improvements.

In order to support flexibility and rapid change, the registry program was built with an open system design rather than one dependent on scripts and protocols, which could be added later. The resulting program has an SQL server back-end with a Microsoft Access front-end. The registry software contains a variety of structured assessments (such as the PHQ-9) that allow for both initial data gathering and serial measurements of important indicators. It allows for the entry and tracking of patient care plans and case notes and generates both patient and care manager level reports. Clinical care managers were initially ambivalent about using the registry because they were anxious about being held accountable for their activities and concerned about the ease with which supervisory staff could monitor productivity and review their care plans and notes. Staff participation in the PDSA cycles, however, helped the care managers to feel more comfortable with the registry as they were part of suggesting and implementing improvements over time. The result has been the successful implementation of a clinical information system that meets the needs of the internal users and provides useful information to providers and executive staff.

\section{Case Study 2: University of Michigan}

The University of Michigan Health System (UMHS) demonstration project, known internally as the Depression in Primary Care program (DPC), includes roughly 100 primary care physicians (family physicians, general internists, and obstetriciangynecologists) from 10 UMHS primary care practices. The 10 sites involved in the DPC program share common infrastructure elements such as a secure email system, electronic billing and scheduling software, and CareWeb, a Web-based clinical data repository holding all UMHS lab information, a text-only problem summary list and text-only outpatient clinical progress notes. The DPC intervention is simple in principle. Each practice develops a relationship with a Care Manager, a trained nurse or social worker, who serves as the link between the patient, their primary care "medical home", and the clinical care, educational, and outcome monitoring resources provided by the project.

\section{Information Technology and Multiple Data Sources}

To support the DPC intervention, we expanded upon two clinical information systems (CIS) prototype applications and created a third CIS, a systemwide depression disease registry. These tools were developed in a collaborative effort of the project team, the UMHS Disease Management Program, and the University of Michigan Depression Center. DPC depression care managers work with the first CIS, the M-DOCC Depression Disease Management Application, in their daily work. This tool is a custom-designed secure client/server application that supports care management and clinical outcome monitoring functions. The current version allows care managers to enter intake information (demographics, clinical history, current and prior treatment), extensive case manager notes, and the depression symptom severity data obtained periodically from patients; the severity data is used to create Patient Outcomes Summary reports that are sent to both the patient and his/her referring primary care physician. This tool also enables us to collect precise data on time spent on selected care manager tasks to support shadow billing for care coordination activities.

Patients interact directly with the second CIS, an Interactive Voice Recognition (IVR)/ Web-based system that collects the core severity and outcome data used to create Patient Outcome Summary Reports. The current IVR script includes 23 items assessing depression severity (PHQ-9), adherence, disability, satisfaction with care, and health-related quality of life (SF-12): the SF-12 is collected every 6 months, the other data collected at each IVR contact. Data collected from IVR is posted to the core M-DOCC application database.

\section{Identifying Eligible Patients for the Registry}

The third CIS, the UMHS depression disease registry, remains a work in progress. Prior to the implementation of the intervention, we created a prototype registry based on the Health Plan Employer Data and Information Set (HEDIS) depression case-finding algorithm applied to claims data for the previous 18 months. At implementation, each clinician at each site was given a list of his or her depression registry patients (patients with a diagnosis of depression- incidence or prevalent cases); clinicians were told that they could refer any 
of these patients to the care manager for evaluation. Our initial data extraction identified about 3600 patients diagnosed with (i.e., claim for) depression in the 10 clinical sites, representing a prevalence of less than $3 \%$. Given that depression is often underdetected, we also subsequently revised the registry using several complementary data sources: self-report screening data from M-Care (the primary health insurer in the project), supplementary billing diagnostic data, and review of coded electronic problem summary lists available at four of the 10 clinical sites. However, this HEDIS-based registry contained a small but significant proportion of falsepositives when we presented clinical data to providers; and hence, we removed these individuals. The revised registry is now continuously updated with all new referrals to DPC. Overall, the creation and validation of a depression registry has been the most difficult aspect of IT support for this disease management effort.

Although the DPC intervention was designed to be implemented in primary care practices that use paper medical records, the coordination of care at the heart of the project has greatly benefited from the presence of an electronic communications infrastructure. All clinicians routinely use a fourth CIS, CareWeb, the Web-based partial EMR in use at UMHS. Its secure links to essentially all clinical databases in UMHS allows clinicians secure access at the point of care (from any terminal capable of Web access) to clinical information ranging from progress notes and discharge summaries to scheduled UMHS appointments to pathology and radiology reports. A secure email system also enables care managers to communicate directly with PCPs and the liaison psychiatrist where necessary, and is one preferred option for transmitting Outcome Summary Reports to PCPs. This database has been an invaluable tool which allows the care manager to use the system from any location and enter patient information which is immediately available to anyone else accessing the system.

Overall, our decision to build communications protocols around email and CareWeb was based upon careful study of clinician work flow at each of our intervention sites and specific clinician feedback. This approach works well within UMHS and will enhance its sustainability in our local setting. As we move beyond UMHS to implement the DPC intervention, we will need to reassess work flow in external primary care sites. It is likely that a Web- based version of the current M-DOCC application will serve as a primary communication tool as well as the core disease monitoring application.

\section{Sustaining the Registry}

It was important from the beginning to implement a registry that could be used for other chronic conditions. Consistent with our guiding principle that disease management programs should be organized around a person rather than a disease, the depression disease registry has been merged with all other current UMHS disease registries and is organized by person. This basic strategy has enabled us to leverage the institutional investment made in disease management to a degree not possible if each program had been developed and maintained independently. The depression disease management process created for the DPC protocol was designed to be part of an integrated disease management registry addressing five common problems (congestive heart failure, coronary artery disease, asthma, diabetes, and depression). Its core CIS infrastructure elements were developed with the intent of exporting them to other programs. Hence, we can now easily determine whether a specific individual qualifies for one, two, or more programs, and can coordinate and integrate interventions. This enables us to minimize potential conflict, inconsistency, and complexity of disease management and we believe will make intervention far more effective in a real world characterized by shifting priorities and competing demands.

The integrated approach we have taken also offers benefits to both patient and provider. From the patient's perspective, the process of disease management - how to contact a program, who to talk to once entered, how to coordinate care for more than one condition, and how monitoring will work - is greatly simplified, particularly if the process is linked to the patient's primary care medical home. We have seen that this is feasible for the majority of patients in each disease management program, and for the large majority of depressed patients in DPC.

From the provider's perspective, disease management will be a unified, simplified service not fragmented into multiple diseases, health plans, or personnel. In the near future, care management for more than one condition will likely be supported by a single trained practice nurse located at the primary 
care site. From the provider's perspective, this approach means that the office has to develop only one new process for its routine work flow, rather than a different process for each disease, each payer, each year. The backbone of this provider-centered approach to disease management in the DPC include the CIS tools and clinical procedures described above. These tools have been designed together to support routine primary care practice operations, and have the potential to be implemented for other patients and conditions.

\section{LESSONS LEARNED}

These case studies highlight some of the key pragmatic factors associated with successful registries in routine practice. Foremost are simplicity, generalizability and privacy. Registries need to be simple in their construction and upkeep and should minimize the workflow requirements necessary between providers and care managers. While depression registries should be developed with an eye towards their generalizability to other chronic conditions, they need to be adapted to the unique circumstances of depression treatment in primary care. A critical issue for patients with depression concerns the role of privacy in data collection and storage in registries. Each of these lessons and their policy implications is described below.

\section{Simplicity: Essential Principles of Registries}

The ultimate registry for application in depression care improvement programs and treatment models should be able to identify and track the treatment and management of patients with depression, and should provide near real-time information on patients' health and treatment status. Registries should be simple to develop and use, integrated into daily clinical activities, contain data relevant to practice and performance measurement, easily updated, and focused on clinical care and not research (Kilbourne et al., 2002). Based on the case studies and experiences of other RWJF sites, a list of essential data elements for a depression care registry is provided in Table 2. Together, these data can be used to: (1) stratify depressed patients by severity level and triage their care to the primary care or specialist sector; (2) provide timely alerts to clinicians and care managers when process measures deviate from established standards; (3) identify patients not responding to initial treatment so that further interventions may be considered, and (4) track outcomes proactively and adjust antidepressant treatment intensity accordingly. In order to develop the optimal registry for their practice, providers need to have a grasp of the available resources and patient population (Table 3 ).

\section{Generalizability of Registries: Are Multi-Disease Registries more Sustainable?}

The University of Michigan DPC program developed a registry for multiple chronic conditions to avoid placing depression and other conditions in separate silos of care management. This reflects a recent trend towards the use of multiple disease registries and multiple risk behavior assessments (Baumgardner and Hindmarsh, 2003). While multiple disease registries can potentially maximize efficiencies, they also create the risk of depression being crowded out relative to physical illnesses (Redelmeier, Tan, \& Booth, 1998). In addition, depression data have unique complexities such as the need for information from behavioral health specialists outside of primary care settings, which can impede data coordination and registry updating. Thus, for multiple disease registries to facilitate the care of depression, they must permit ready communication between PCPs and behavioral health specialists. This may require both provider types to establish standards that ensure patient privacy (e.g., based on the HIPAA Privacy rule).

\section{Patient Privacy}

Safeguarding the privacy of personal health information in an era of multiple disease registries and instantaneous electronic communication demands the attention of any care system planning the expansion of clinical information services. Concerns about violating patient privacy should be addressed and rectified from the beginning when implementing depression registries. The fragmentation of physical and behavioral healthcare makes it more difficult to assure privacy when obtaining and sharing comprehensive data on patient care without apriori agreements between multiple providers. One potential solution adapted by the RWJF sites is to require patients and providers jointly to sign release of information and privacy forms. 
Table 2. Essential Depression Care Registry Data Elements

\begin{tabular}{|c|c|}
\hline Field & Response Options \\
\hline \multicolumn{2}{|l|}{ General information (entered once) } \\
\hline Patient Last Name & $<$ name $>$ \\
\hline Patient First Name & $<$ name $>$ \\
\hline Patient ID & $<\mathrm{ID}>$ \\
\hline $\begin{array}{l}\text { Psychiatrist or mental health } \\
\text { provider }\end{array}$ & $<$ provider name $>$ \\
\hline Primary care provider & $<$ provider name $>$ \\
\hline Primary Contact Numbers & (phone \#1; phone \#2> \\
\hline Best time to call & $<\# \#: \# \#$ AM/PM > \\
\hline OK to leave message? & $<$ yes or no $>$ \\
\hline \multicolumn{2}{|l|}{$\begin{array}{l}\text { Contact (Encounter)-specific } \\
\text { information }\end{array}$} \\
\hline Contact or visit date & $\mathrm{mm} / \mathrm{dd} /$ yyyy \\
\hline Provider at visit & $\begin{array}{l}<\text { PCP, Care manager, } \\
\text { Mental health specialist, } \\
\text { other }>\end{array}$ \\
\hline Visit/call & $\begin{array}{l}<\text { Call, visit, no-show, } \\
\text { unreachable }>\end{array}$ \\
\hline Primary reason of visit & $\begin{array}{l}\text { Medical (specify); Psychiatric } \\
\text { (specify) }\end{array}$ \\
\hline $\begin{array}{l}\text { Current Depressive } \\
\text { Symptoms* }\end{array}$ & List symptoms \\
\hline $\begin{array}{l}\text { Current/past smoking, } \\
\text { tobacco use }\end{array}$ & $<$ yes or no $>$ \\
\hline $\begin{array}{l}\text { Alcohol and illicit drug } \\
\text { use-current }\end{array}$ & $<$ yes or no $>$ \\
\hline Psychotic features & Yes/No \\
\hline Patient-reported side effects & Checklist of side effects \\
\hline Provider's assessment & $<$ text $>$ \\
\hline Suicidal Ideation? & $\begin{array}{l}<\text { yes or no }>\text { If Yes, action } \\
\text { taken: }\end{array}$ \\
\hline Comorbidities & Medical comorbidities (list) \\
\hline Treatment options discussed & $\begin{array}{l}\text { Pharmacotherapy; } \\
\text { Psychotherapy; and/ } \\
\text { or Other; no tx }\end{array}$ \\
\hline Treatment initiated & $\begin{array}{l}\text { Pharmacotherapy; } \\
\text { Psychotherapy; Other; } \\
\text { No tx }\end{array}$ \\
\hline Current medication and dose & (list meds or check off $\mathrm{Rx}$ ) \\
\hline Treatment adherence & $\begin{array}{l}\text { \# of pills missed -past } 4 \text { days; } \\
\text { Prescription refilled? }\end{array}$ \\
\hline Was medication SWITCHED? & $\begin{array}{l}<\text { yes or no }>\text { If Yes, } \\
\text { new medication: }\end{array}$ \\
\hline Any Counseling Provided & $<$ yes or no $>$ \\
\hline Other Therapy Provided & $<$ yes or no > ; If yes: describe: \\
\hline Referral & Date \\
\hline $\begin{array}{l}\text { Patient seen at referral } \\
\text { provider? }\end{array}$ & $<$ yes or no > ; If no; why? \\
\hline Summary of this current visit & $<$ comments $>$ \\
\hline Self-management goals & $<$ comments $>$ \\
\hline Next scheduled contact type & Call/Visit \\
\hline Next contact date & $\mathrm{mm} / \mathrm{dd} /$ yyyy \\
\hline
\end{tabular}

*Use self-reported depressive symptom assessment such as the Patient Health Questionnaire, CES-D, etc.
Table 3. Customizing the Registry to Practices: What Providers and Leaders Need to Know

Know your stakeholders and get their input- Including purchasers and payers

Know your patient population - Case mix, and where they get care

Know your key data sources - What is in the administrative datasets?; To what extent do they capture utilization across your patient population?

Know what information technologies are available and whether they can be tailored to depression care (e.g., Web-based patient health risk assessments)

Know your end users (e.g., care managers, clinic staff, providers), including their work flow, and ensure they can work with the registry on a day-to-day basis

Know what stakeholders want in terms of outcomes: What quality and cost measures are they interested in, and use registry to enhance performance measures

\section{IMPLICATIONS FOR PRACTICE AND POLICY}

The backbone of depression and any other chronic illness care management process is a robust clinical information system that:

- Coordinates treatment by tracking patients and their appointments, follow-up sessions, referrals, test results other and assessments

- Facilitates communication between patients, primary and specialty providers and care managers

- Helps patients and clinicians determine treatment preferences

- Assists patients establish realistic selfmanagement goals

- Connects patients and families to community resources

- Tracks both clinical and financial outcomes

These functions place patient information registries at the core of efforts to improve depression treatment in primary care and can thereby influence healthcare practice and policy decision-making (Fig. 1). For example, registries can provide health plans and purchasing coalitions with the prerequisite information necessary to implement "pay for performance" incentive programs that link clinical measures with financial rewards. Data from registries also can be used to allocate personnel resources, facilitate provider education, monitor patient populations to identify those at risk for suicide and make the "business case" to stakeholders by documenting the value 


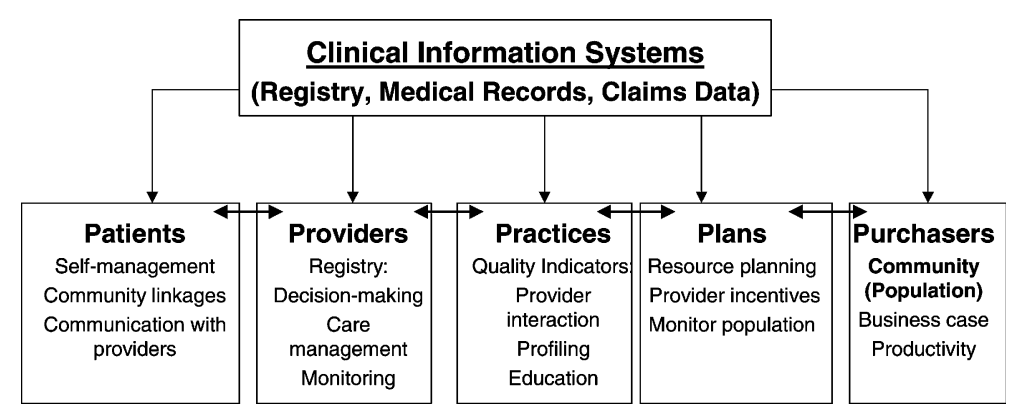

Fig. 1. The Role of Information System in Facilitating Depression Management Across the Healthcare System.

of improving depression care (Pincus, Hough, Houtsinger, Rollman, \& Frank, 2003).

As traditional paper-based medical records systems continue morphing into powerful, relational databases, opportunities to identify, sort, and merge patient populations by disease states, genetic idiosyncrasies, insurance coverage, etc. will increase exponentially. The risk of divulging personal health information and using it (inappropriately or illegally) for income or to discriminate will increase proportionately. Healthcare executives, elected officials and consumer advocates will face heady challenges in organizing emerging technological innovations in ways that promote disease prevention and management, rather than excessive profit and identity theft.

\section{CONCLUSIONS}

Patient information registries and other technology solutions to recording medical data have the potential to improve the management and, ultimately, the outcomes of depression care. Still, many primary care practices have been reluctant to implement registries for depression care as rapidly as they have for other chronic illnesses. Nonetheless, as seen in the case studies, simple registries can be created or adapted for successful use in primary care settings without relying on expensive alternatives. Other advances in information technology, such as secure, web-based communications, have the potential to improve coordination of depression care services across multiple sites and in rural areas. The inevitable proliferation of these information technology solutions must be coupled with dedicated efforts by practitioners, health plan executives, and purchasers to assure patient privacy. Finally, registries and other information tools provide an ideal opportunity for the systemic collection of patient-level information that can be used to guide new compensation contingencies and inform policymakers.

\section{ACKNOWLEDGMENTS}

This research reported here was supported by the Robert Wood Johnson Foundation Depression in Primary Care Incentives Demonstration Program (H. Pincus, PI). Dr. Kilbourne is funded by a Career Development Award Merit Review Entry Program from the VA Health Services Research and Development program.

\section{REFERENCES}

Allenby, A., Matthews, J., Beresford, J. J., \& McLachlan, S. A. (2002). The application of computer touch-screen technology in screening for psychosocial distress in an ambulatory oncology setting. European Journal of Cancer Care, 11, 245253.

Bartels, S. J., Dums, A. R., Oxman, T. E., Schneider, L. S., Arean, P. A., Alexopoulos, G. S., \& Jeste, D. V. (2002). Evidencebased practices in geriatric mental health care. Psychiatric Services, 53, 1419-1431.

Baumgardner G., \& Hindmarsh M. F. (2003). Evaluate physician office registries special study. June 23, 2003. Qualis Health (Document Number 7SOW-WA-OUTPT-03-14).

Bodenheimer, J. C., Robinson, T., Goldberg, H. I., Ralston, J. D., Hirsch, I. B., Hoath, J. I., \& Ahmed, K. I. (2003). Using an Internet comanagement module to improve the quality of chronic disease care. Joint Commission Journal on Quality and Safety, 29, 443-451.

Bodenheimer, T., Wang, M. C., Rundall, T. G., Shortell, S. M., Gillies, R. R., Oswald, N., Casalino, L., \& Robinson, J. C. (2004). What are the facilitators and barriers in physician organizations' use of care management processes?. Joint Commission Journal on Quality and Safety, 30, 505-514.

Bruce, M., TenHave, T., Reynolds, C. F., Katz, I., Schulberg, H. C., Mulsant, B. H., Brown, G., McAvoy, G., Pearson, J., \& Alexopolous, G. (2004). A randomized trial to reduce suicidal ideation and depressive symptoms in older primary care patients: the PROSPECT Study. Journal of the American Medical Association, 291, 1081-1091.

Cannon, D. S., \& Allen, S. N. (2000). A comparison of the effects of computer and manual reminders on compliance with a 
mental health clinical practice guideline. Journal of the American Medical Informatics Association, 7, 196-203.

Casalino, L., Gillies, R. R., Shortell, S. M., Schmittdiel, J. A., Rundall, T., Oswald, N., Schauffler, H., \& Wang, M. C. (2003). External incentives, information technology, and organized processes to improve health care quality for patients with chronic diseases. Journal of the American Medical Association, 289(4), 434-441.

Dietrich A. J., Oxman T. E., Williams J. W., Schulberg H. C., Bruce M. L., Lee P. W., Barry S., Lefever P. J.J., Heo M., Rost K., Kroenke K., Gerrity M., \& Nutting P. (in press, 2004). Re-Engineering systems for the primary care treatment of depression: a randomized, controlled trial. British Medical Journal.

Feifer, C., Ornstein, S. M., Nietert, P. J., \& Jenkins, R. G. (2001). System supports for chronic illness care and their relationship to clinical outcomes. Top Health Information Management, $22,65-72$.

Goldberg, H. I., Ralston, J. D., Hirsch, I. B., Hoath, J. I., \& Ahmed, K. I. (2003). Using an internet comanagement module to improve the quality of chronic disease care. Joint Commission Journal on Quality and Safety. 29, 443-451.

Hunkeler, E. M., Westphal, J. R., \& Williams, M. (1995). Developing a system for automated monitoring of psychiatric outpatients: A first step to improve quality. HMO Practice, 9 , 162-167.

Hunkeler, E. M., Meresman, J., Hargreaves, W. A., Fireman, B., \& Berman, W. (2000). Effectiveness of nurse telehealth and peer support in augmenting SSRI treatment of depression in primary care. Archives of Family Medicine, 9, 100-105.

Hynes, D. M., Cowper, D., Kerr, M., Kubal, J., \& Murphy, P. A. (2000). Database and informatics support for QUERI: current systems and future needs. Quality enhancement research initiative. Medical Care, 38, I114-128.

Institute of Medicine. (2001). Crossing the Quality Chasm. Washington D. C.: National Academy Press.

Katon, W., Von Korff, M., Lin, E. H.B., Simon, G., Walker, E., Unutzer, J., Bush, T., Russo, J., \& Ludman, E. (1999). A randomized trial of stepped collaborative care for primary care patients with persistent symptoms of depression. Archives of General Psychiatry, 56, 1109-1115.

Kilbourne, A. M., Rollman, B. L., Schulberg, H. C., Herbeck-Belnap, B., \& Pincus, H. A. (2002). A clinical framework for depression treatment in primary care. Psychiatric Annals, 32, $545-553$.

Kilbourne A. M., Schulberg H. C., Post E. P., Rollman B. L., Herbeck-Belnap B., \& Pincus H. A. (2004). Translating evidence-based depression-management services to communitybased primary care practices. Milbank Quarterly, 82, 631-659.

Mechanic, D. (2002). Improving the quality of health care in the United States of America: The need for a multi-level approach. Journal of Health Services Research and Policy, 7(Suppl 1), S35-S39.

Moreland, M. E., Kilbourne, A. M., Engelhardt, J. B., Jain, R., Gao, J., Macpherson, D. S., Sonel, A. F., \& Xing, G. (2004). Diabetes preventive care and non-traumatic lower extremity amputation rates. Journal of Healthcare Quality, 26, 12-17.

Nobel, J. J., \& Norman, G. K. (2003). Emerging information management technologies and the future of disease management. Disease Management, 6, 219-231.

Owen, R. R., Thrush, C. R., Cannon, D., Sloan, K. L., Curran, G., Hudson, T., Austen, M., \& Ritchie, M. (2004). Use of elec- tronic medical record data for quality improvement in schizophrenia treatment. Journal of the American Medical Informatics Association, 11, 351-357.

Pincus, H. A., Pechura, C. M., Elinson, L., \& Pettit, A. R. (2001). Depression in primary care: Linking clinical and systems strategies. General Hospital Psychiatry, 23, 311-318.

Pincus, H. A., Hough, L., Houtsinger, J. K., Rollman, B. L., \& Frank, R. G. (2003). Emerging models of depression care: multi-level ('6 P') strategies. International Journal of Methods in Psychiatric Research, 12, 54-63.

Redelmeier D. A., Tan S. H., \& Booth G. L. (1998). The treatment of unrelated disorders in patients with chronic medical diseases. New England Journal of Medicine 338:1516-1520.

Rollman, B. L., Hanusa, B. H., Gilbert, T., Lowe, H. J., Kapoor, W. N., \& Schulberg, H. C. (2001). The electronic medical record. A randomized trial of its impact on primary care physicians' initial management of major depression. Archives of Internal Medicine, 161, 189-197.

Rost, K., Nutting, P. A., Smith, J., \& Werner, J. J. (2000). Designing and implementing a primary care intervention trial to improve the quality and outcome of care for major depression. General Hospital Psychiatry, 22, 66-77.

Rost, K. M., Duan, N., Rubenstein, L. V., Ford, D. E., Sherbourne, C. D., Meredith, L. S., \& Wells, K. B. (2001). The quality improvement for depression collaboration: General analytic strategies for a coordinated study of quality improvement in depression care. General Hospital Psychiatry, 23, 239-253.

Rubenstein, L. V., Parker, L. E., Meredith, L. S., Altschuler, A., dePillis, E., Hernandez, J., \& Gordon, N. P. (2002). Understanding team-based quality improvement for depression in primary care. Health Services Research, 37(4), 1009-1029.

Simon, G., Von Korff, M., Rutter, C., \& Wagner, E. (2000). Randomised trial of monitoring, feedback, and management of care by telephone to improve treatment of depression in primary care. British Medical Journal, 320, 550-554.

Simon, G. E., Ludman, E. J., Tutty, S., Operskalski, B., \& Von Korff, M. (2004). Telephone psychotherapy and telephone care management for primary care patients starting antidepressant treatment: a randomized controlled trial. Journal of the American Medical Association, 292, 935-942.

Sperl-Hillen, J. M., Solberg, L. I., Hroscikoski, M. C., Crain, A. L., Engebretson, K. I., \& O'Connor, P. J. (2004). Do all components of the chronic care model contribute equally to quality improvement?. Joint Commission Journal on Quality and Safety, 30, 303-309.

Unutzer, J., Choi, Y., Cook, I. A., \& Oishi, S. (2002). A web-based data management system to improve care for depression in a multicenter clinical trial. Psychiatric Services, 53, 671-673.

Wagner, E. H., Austin, B. T., \& Von Korff, M. (1996). Organizing care for patients with chronic illness. Milbank Quarterly, 74, 511544.

Wagner, E. H., Austin, B. T., Davis, C., Hindmarsh, M., Schaefer, J., \& Bonomi, A. (2001). Improving chronic illness care: Translating evidence into action. Health Affairs (Millwood), 20, 64-78.

Wells, K. B., Sherbourne, C., Schoenbaum, M., Duan, N., Meredith, L., Unutzer, J., Miranda, J., Carney, M. F., \& Rubenstein, L. V. (2000). Impact of disseminating quality improvement programs for depression in managed primary care: A randomized controlled trial. Journal of the American Medical Association, 283, 212-20. 